\title{
Analysis of BMP4 and BMP7 signaling in breast cancer cells unveils time-dependent transcription patterns and highlights a common synexpression group of genes
}

Alejandra Rodriguez-Martinez ${ }^{1 \dagger}$, Emma-Leena Alarmo ${ }^{1 \dagger}$, Lilli Saarinen$^{2}$, Johanna Ketolainen ${ }^{1}$, Kari Nousiainen$^{2}$, Sampsa Hautaniemi ${ }^{2}$ and Anne Kallioniemi ${ }^{i^{*}}$

\begin{abstract}
Background: Bone morphogenetic proteins (BMPs) are members of the TGF-beta superfamily of growth factors. They are known for their roles in regulation of osteogenesis and developmental processes and, in recent years, evidence has accumulated of their crucial functions in tumor biology. BMP4 and BMP7, in particular, have been implicated in breast cancer. However, little is known about BMP target genes in the context of tumor. We explored the effects of BMP4 and BMP7 treatment on global gene transcription in seven breast cancer cell lines during a 6point time series, using a whole-genome oligo microarray. Data analysis included hierarchical clustering of differentially expressed genes, gene ontology enrichment analyses and model based clustering of temporal data.

Results: Both ligands had a strong effect on gene expression, although the response to BMP4 treatment was more pronounced. The cellular functions most strongly affected by BMP signaling were regulation of transcription and development. The observed transcriptional response, as well as its functional outcome, followed a temporal sequence, with regulation of gene expression and signal transduction leading to changes in metabolism and cell proliferation. Hierarchical clustering revealed distinct differences in the response of individual cell lines to BMPs, but also highlighted a synexpression group of genes for both ligands. Interestingly, the majority of the genes within these synexpression groups were shared by the two ligands, probably representing the core molecular responses common to BMP4 and BMP7 signaling pathways.
\end{abstract}

Conclusions: All in all, we show that BMP signaling has a remarkable effect on gene transcription in breast cancer cells and that the functions affected follow a logical temporal pattern. Our results also uncover components of the common cellular transcriptional response to BMP4 and BMP7. Most importantly, this study provides a list of potential novel BMP target genes relevant in breast cancer.

Keywords: bone morphogenetic protein, breast cancer, BMP4, BMP7, expression microarray

\section{Background}

Bone morphogenetic proteins (BMPs) are extracellular ligand molecules that belong to the transforming growth factor $\beta$ (TGF- $\beta$ ) superfamily. To date, 21 members of the human BMP family have been identified [1]. BMPs

\footnotetext{
* Correspondence: anne.kallioniemi@uta.fi

† Contributed equally

'Laboratory of Cancer Genetics, Institute of Biomedical Technology, University of Tampere and Centre for Laboratory Medicine, Tampere University Hospital, Finland

Full list of author information is available at the end of the article
}

regulate transcription of target genes by signaling through type I and II transmembrane serine-threonine receptors. Binding of the ligand to the type II receptor elicits phosphorylation of the type I receptor, which, as a result, is able to phosphorylate other molecules and transmit the signal. In the canonical BMP pathway, the type I receptor phosphorylates receptor-regulated SMAD (homologue of Drosophila Mothers Against Decapentaplegic) proteins (R-SMADs, SMAD-1/5/8), which then bind to the common mediator SMAD4; the

\section{() Biomed Central}


resulting SMAD complex translocates to the nucleus to regulate transcription of target genes [1]. The signals generated by BMPs in the cell membrane may be also transferred into the cell via ERK, JNK and p38 mitogenactivated protein kinases (MAPK) [2,3]. Moreover, there is crosstalk between BMP signaling and other cellular signaling cascades, such as the Wnt, JAK/STAT and Notch pathways [4-6].

BMPs were first identified as inducers of ectopic bone formation in vivo [7] but were later found to be crucial multifunctional regulators of development [8]. During the last decade, the role of BMPs in cancer development has gained increasing interest [9-11]. The importance of BMP4 and BMP7 in breast cancer was highlighted in a survey of seven BMPs: these two ligands had the highest expression levels and were the most frequently expressed among 22 cell lines and 39 primary tumor samples [12]. The expression of BMP4 and BMP7 in breast cancer also has been demonstrated in several other reports [13-17]. Interestingly, BMP7 protein expression in primary breast tumors has been associated with accelerated bone metastasis formation and served as an independent prognostic factor for early bone metastasis in a study based on a set of 409 patient samples [15] though, with a smaller set of 67 patient samples, this association was not established [18].

The functional significance of BMP4 and BMP7 in breast cancer has been studied predominantly through the use of in vitro models. BMP4 was shown to inhibit cell proliferation in a panel of breast cancer cell lines by inducing a G1 cell cycle arrest [14]. The effects of exogenous BMP4 on breast cancer cell migration and invasion have also been studied. For the most part, the data suggest promotion of these cellular abilities by BMP4 in several breast cancer cell lines and in normal breast epithelial cells $[14,19]$, while a study in which only MDA-MB-231 cells were analyzed reported the opposite phenotype [20]. For BMP7, the results from different reports and different cell lines are more variable. In vitro examination of BMP7 manipulation have revealed cell line-specific effects on cell proliferation, migration and invasion; BMP7 induces all of these parameters in MDA-MB-231 cells and inhibits cellular proliferation in several other cell lines [21]. In opposition, in an in vivo xenograft mouse model of MDA-MB-231 cells, BMP7 reduced tumor growth as well as the formation and growth of bone metastases [18].

In spite of the many years since the discovery of BMPs and being currently a very active topic in cancer research, little is known about their target genes in tumor conditions. The present study was designed to gain knowledge in this topic, by exploring the effects of BMP4 and BMP7 signaling on gene transcription in seven breast cancer cell lines and throughout a 6-point time series, using a genome-wide approach. We characterized the transcriptional response of breast cancer cells to BMP signaling in an analysis that included a temporal dimension and the comparison of different cell lines and two BMP ligands. Finally and most importantly, we report novel potential BMP target genes relevant in breast cancer.

\section{Methods}

\section{Breast cancer cell lines}

Seven breast cancer cell lines (HCC1954, MDA-MB-361, ZR-75-30, HCC1419, SK-BR-3, MDA-MB-231 and T47D) were purchased from the American Type Culture Collection (ATCC, Manassas, VA) and cultured according to the recommended conditions except for MDAMB-231 and T-47D, for which the concentration of FBS in culture media were $1 \%$ and $5 \%$, respectively.

\section{BMP4 and BMP7 treatments}

Recombinant human BMP4 and BMP7 proteins were purchased from R\&D Systems (Minneapolis, MN). Three cell lines (HCC1954, MDA-MB-361 and ZR-7530) were treated with both BMP4 $(100 \mathrm{ng} / \mathrm{ml})$ and BMP7 (50 ng/ml) separately. HCC1419 and SK-BR-3 cell lines received only BMP4 treatment $(100 \mathrm{ng} / \mathrm{ml})$, while MDA-MB-231 and T-47D were treated only with BMP7 $(50 \mathrm{ng} / \mathrm{ml})$. Cells were seeded on 24-well plates, allowed to adhere for $24 \mathrm{~h}$, and treated with the BMP ligand or vehicle for $30 \mathrm{~min}, 1 \mathrm{~h}, 3 \mathrm{~h}, 6 \mathrm{~h}, 12 \mathrm{~h}$ and 24 $\mathrm{h}$ (Figure 1A). Experiments were performed in triplicate and collected cells were pooled.

\section{Microarrays}

Total RNA was extracted using the RNeasy Mini Kit (Qiagen, Valencia, CA) and the quality of RNA was validated using the Agilent RNA 6000 Nano Kit (Agilent Technologies, Palo Alto, CA, USA). Total RNA (500 ng) was used to generate fluorescent $\mathrm{Cy}$-3-(vehicle treated cells) or Cy-5-labeled cRNA (BMP4- or BMP7-treated cells) using the Agilent Low RNA Input Fluorescence Linear Amplification Kit (Agilent Technologies). The labeled cRNAs were hybridized to the $44 \mathrm{~K}$ Whole Human Genome oligo microarrays (Agilent Technologies) according to the manufacturer's protocol. Microarray slides were scanned (Agilent Microarray Scanner) after hybridization, and data were extracted using the Feature Extraction software, version A.7.5.1 (Agilent Technologies). The microarray data has been submitted to the GEO database (accession number GSE31605).

\section{Data analysis}

The microarray data were first subjected to linear normalization to allow comparison between arrays. All probes were compared to the reference sequence using 

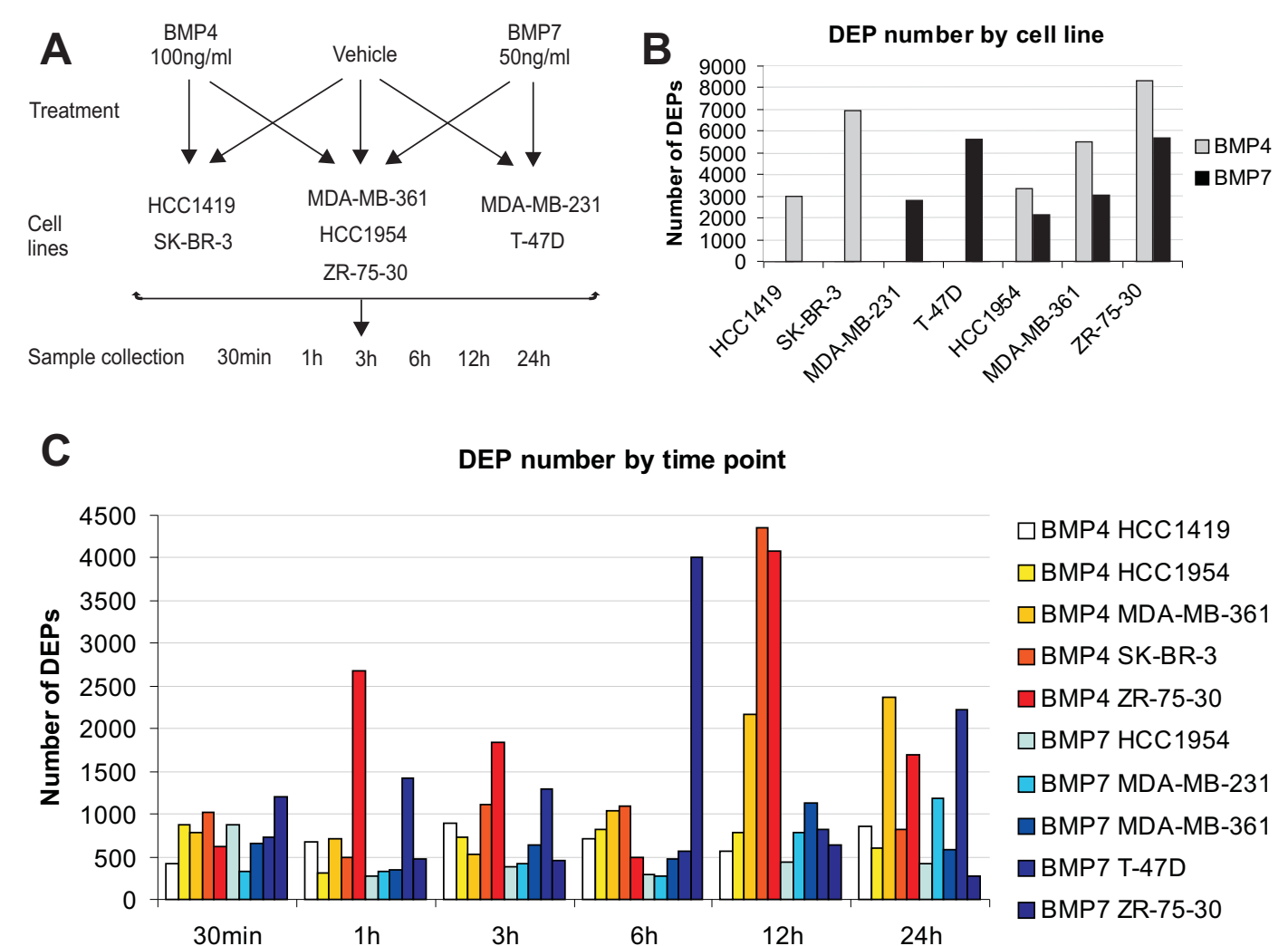

Figure 1 Experimental workflow and numbers of differentially expressed probes (DEPs) resulting from BMP4 or BMP7 treatment. (A) Seven breast cancer cell lines were cultured on 24-well plates, allowed to adhere for $24 \mathrm{~h}$, and treated with the BMP ligand or vehicle for 30 min, 1 h, 3 h, 6 h, 12 h, and 24 h. Experiments were performed in triplicate, and collected cells were pooled. (B) The expression data from each cell line were individually filtered according to the following criteria: differential expression of at least 2-fold at a minimum of one time point. The number of DEPs per cell line is represented. (C) The expression data from individual time points of every cell line were filtered according to a 2-fold cutoff in expression change. The number of DEPs per time point is shown.

BLAST (v.2.2.23). Ensembl IDs for the probes were obtained by examining the probe's genomic location. The Ensembl Homo sapiens database version $60.37 \mathrm{e}$ was used. This process resulted in the annotation of $84 \%$ of all the probes. A total of $66 \%$ of the probes mapped uniquely to genes and 16\% mapped to multiple genes.

In order to determine differentially-expressed genes, expression data were subjected to three types of filtering: cell line-specific, time point-specific and general filtering. Cell line-specific filtering was done separately for each cell line, following the criteria of a differential expression of at least 2-fold in a minimum of one time point. In the time point-specific filtering, data from each time point were independently filtered according to a 2-fold expression change cutoff. General filtering was performed on all the data from all the cell lines together (separately for BMP4 and BMP7) following the next criteria: probes with a differential expression of at least 3-fold in at least three events and/or 2-fold in at least four events were considered for subsequent analysis. An event refers to any time point of any cell line, resulting in a maximum number of 30 events ( 5 cell lines and 6 time points per cell line). The data sets produced by general filtering were further hand-annotated to reduce the number of probes with multiple annotations. Uniquely annotated probes are designated hereafter as "genes, "whereas the terms "probe" and "genetic element" refer to multiple annotated probes or any data including them. The gene lists resulting from general filtering were ranked according to the number of events in which they showed regulation. Furthermore, all the probes derived from general filtering were subjected to hierarchical clustering using correlation metrics, agglomerative strategy and average linkage method.

Enrichments of gene ontology (GO) terms were performed on several data sets applying Fisher's exact test and using all genes present on the microarray as a reference [22]. In all the GO enrichment analyses, only probes with unique annotation were used. 
A model-based clustering method [23] that allows the finding of clusters of genes with similar expression profiles was performed using MCLUST R package [24]. This method was applied to data resulting from cell line-specific filtering. Data were $\log 2$-transformed and scaled to unit length. In the model-based clustering method, the clusters are considered to be groups displaying multivariate distributions. Several models were fitted to the data. The selections of the best model and the number of clusters were made based upon maximizing Bayesian Information Criterion (BIC) values for the specific model and number of clusters that best represented the data. The data analyses were performed using the Anduril data analysis framework [25] and R [26].

\section{Results}

The aim of this study was to uncover the transcriptional responses of BMP4 and BMP7 signaling in breast cancer. To this end, we selected breast cancer cell lines with low endogenous expression of BMP4 (HCC1419, SK-BR-3), BMP7 (MDA-MB-231, T-47D) or both (HCC1954, MDA-MB-361, ZR-75-30) [12,14] and treated them with the corresponding BMP ligand (rhBMP4 or rhBMP7) and vehicle controls (Figure 1A). Global gene expression levels were analyzed at six different time points from $30 \mathrm{~min}$ to $24 \mathrm{~h}$ in order to reveal the temporal patterns of transcriptional changes.

\section{Overall transcriptional response to BMP4 and BMP7 treatment}

Due to the multidimensional nature of our data, we used three different filtering approaches, each of them allowing analysis from a different perspective. Cell linespecific analysis of the expression data evidenced considerable variation in the number of differentially expressed probes (DEPs) from one cell line to another (Figure 1B), implicating distinct differences in their transcriptional response to BMPs. Further evaluation of these results revealed that BMP4 treatment resulted in greater amounts of DEPs than BMP7 (average number of DEPs per cell line: 5, 469 versus 3, 898 for BMP4 and BMP7, respectively; Figure $1 \mathrm{~B}$ ). This finding could not be explained by the differences in cell lines used to study the two ligands, as a similar outcome was observed in the three lines treated with both BMP4 and BMP7 (HCC-1954, MDA-MB-361 and ZR-75-30). Time point-specific filtering revealed clear temporal variation in the number of DEPs (Figure $1 \mathrm{C}$ ). Generally, there was a tendency towards a greater amount of DEPs at later time points. In order to focus our attention especially on those genes whose expression was most consistently and extensively affected by BMP4 and BMP7 signaling, we performed a general filtering of the expression data according to the following criteria: fold change $(\mathrm{FC}) \geq+/-3$ in at least 3 events and/or $\mathrm{FC} \geq$ $+/-2$ in at least 4 events. This resulted in the identification of 2, 421 and 1, 263 differentially expressed gene elements (1, 678 and 905 uniquely annotated probes) for BMP4 and BMP7 experiments respectively, further evidencing a more prominent effect of BMP4 than BMP7 on gene transcription.

Unsupervised hierarchical clustering on the data sets resulting from general filtering (BMP4 and BMP7 separately) revealed that the samples originating from a particular cell line mainly clustered together (Figure 2), suggesting considerable variation in the response of individual cell lines to BMPs. The most obvious examples are MDA-MB-361, ZR-75-30, and HCC1419 (for BMP4) as well as MDA-MB-361 and HCC1954 (for BMP7). Clustering according to time point was an uncommon phenomenon, but it was observed for the samples derived from MDA-MB-231, ZR-75-30, HCC1954 and T-47D after 30 min of BMP7 treatment (Figure 2B). At the probe level, both BMP4 and BMP7 hierarchical trees revealed a small subset of gene elements that clustered tightly together (named clusters A and B hereafter, Figure 2, blue boxes). However, it is important to note that the expression of the genes in these clusters was not altered in a similar fashion in all the cell lines; rather, they were upregulated in some cell lines and downregulated in others, showing diverse temporal patterns. For both ligands, these clusters appeared to dictate the division of the samples into two major tree branches (Figure 2).

In order to obtain a general view of the cellular functions regulated as a result of BMP4 and BMP7 signaling in breast cancer cell lines, we performed a GO enrichment analysis on the data sets resulting from general filtering. As might have been expected, functional categories related to regulation of transcription were among the most highly enriched for both ligands. Additionally, genes involved in organ development were abundantly regulated as a result of stimulation with either ligand. In this regard, BMP4 seemed more often to regulate genes involved in skeletal system development (Table 1), while BMP7, on the other hand, appeared to regulate genes involved in epithelial development, neurogenesis and tube development (Table 2).

\section{A common synexpression group of genes regulated in response to BMP4 and BMP7 signaling}

As mentioned above, hierarchical clustering unveiled gene clusters A (BMP4, containing 329 probes) and B (BMP7, 228 probes) with highly correlated expression patterns (Figure 2, blue boxes). Interestingly, of all the probes contained in clusters A and B, 210 (154 genes with known and unique annotation, named group $\mathrm{C}$ 


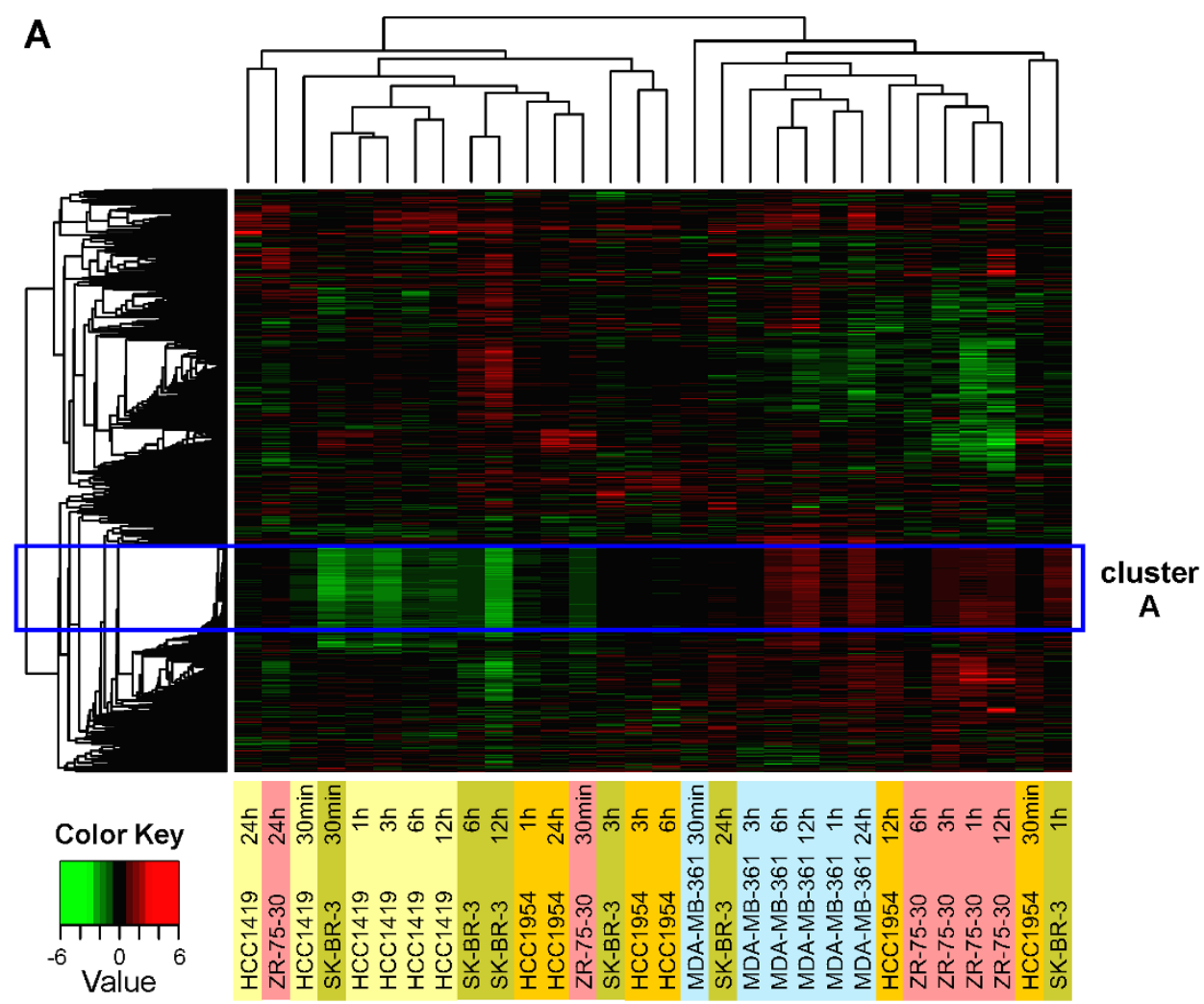

B

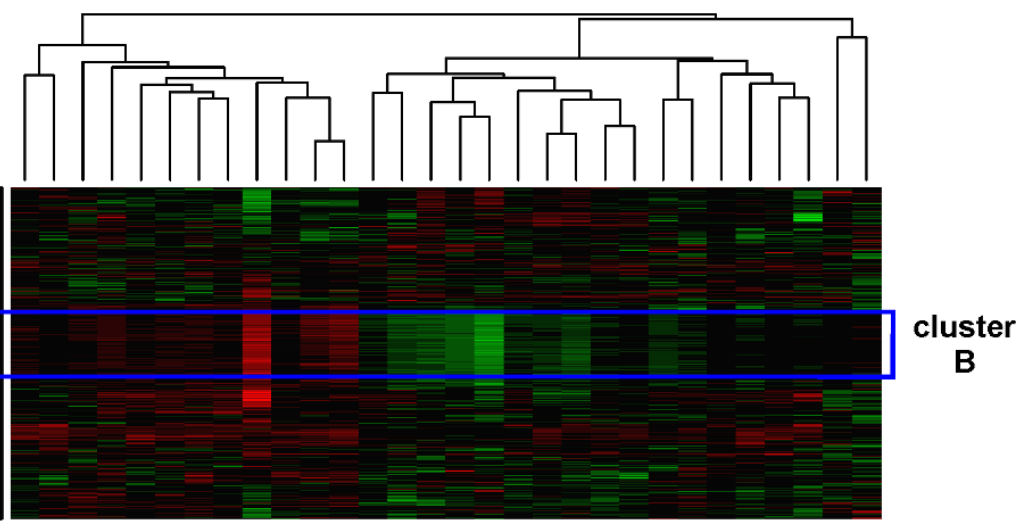

Color Key

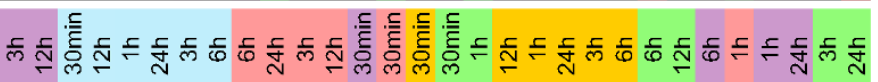

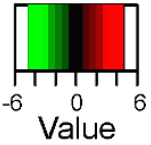

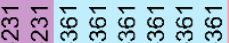

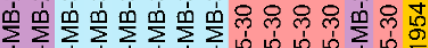

苋芯芯芯芯

กิ $\overline{\mathrm{N}} \overline{\mathrm{N}}$

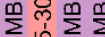

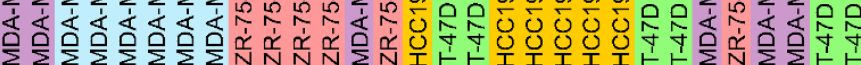

Figure 2 Unsupervised hierarchical clustering of microarray data. The data sets resulting from general filtering (2, 421 probes for (A) BMP4 and 1, 263 probes for (B) BMP7) were subjected to this analysis. For both ligands, there is an evident cluster of gene elements showing very highly correlated expression patterns throughout the samples (gene clusters A and B, blue boxes).

hereafter, Additional file 1) were present in both clusters and thus represent shared BMP target genes. Direct comparisons of the expression patterns of group $\mathrm{C}$ probes in the three cell lines (HCC1954, MDA-MB-361 and ZR-75-30) treated with both ligands revealed elements of similarity between BMP4 and BMP7 response in the same cell line but high variability between different cell lines (Figure 3). For example, these genes were 
Table 1 Enriched gene ontology categories for differentially expressed genes as a result of BMP4 treatment.

\begin{tabular}{|c|c|c|}
\hline Category & Number of genes & $p$-Value \\
\hline \multicolumn{3}{|l|}{ Biological process } \\
\hline GO:0006355: regulation of transcription, DNA-dependent & 240 & 0.005 \\
\hline GO:0009888: tissue development & 128 & 0.014 \\
\hline GO:0001501: skeletal system development & 53 & 0.031 \\
\hline GO:0030154: cell differentiation & 237 & 0.041 \\
\hline \multicolumn{3}{|l|}{ Molecular function } \\
\hline GO:0043565: sequence-specific DNA binding & 94 & 0.043 \\
\hline GO:0003700: sequence-specific DNA binding transcription factor activity & 133 & 0.046 \\
\hline
\end{tabular}

commonly upregulated in MDA-MB-361 while downregulated in HCC1954. The GO enrichment analysis unveiled 23 enriched biological process terms, of which 21 could be classified into two functional categories, namely development and morphogenesis (16 terms) and gene expression (5 terms) (Additional file 2).

\section{Temporal patterns of transcriptional response to BMP signaling}

Model-based clustering analysis of the expression data was performed to distinguish clusters of genes with similar temporal profiles of expression. With this method we identified 12 to 22 probe clusters for each cell line and these clusters could be subsequently classified into four main categories (Tables 3 and 4 and Additional file 3). Gene elements that were first regulated at $30 \mathrm{~min}$ or $1 \mathrm{~h}$ were classified as early, $3 \mathrm{~h}$ or $6 \mathrm{~h}$ earlyintermediate, and $12 \mathrm{~h}$ late-intermediate responders, regardless of their expression at later time points. Late responders included those probes differentially expressed exclusively at the $24 \mathrm{~h}$ time point. Representative examples of clusters in the different temporal categories are depicted in Figure $4 \mathrm{~A}$ and 4B.

We had already explored the biological functions of the genes differentially expressed upon BMP treatment. As we were now able to temporally classify the genes, we became interested in evaluating whether temporal patterns of expression and gene function could be related. Therefore, we grouped the clusters from each temporal category (early, early-intermediate, late-intermediate, and late) and performed GO enrichment analyses on the genes within these groups (Additional file 3). Finally, results from the different cell lines were combined. Although enriched GO terms were not found in every temporal stage of every cell line, many GO terms were enriched in the four temporal categories for BMP4 (Figure $4 \mathrm{C}$ ). Of all the functional terms enriched throughout the experiments, those related to development were especially abundant in the early and early-intermediate phases. Terms connected with regulation of gene expression appeared at all times, although they were less abundant at the late stage of $24 \mathrm{~h}$. Metabolism-associated terms were also present throughout the experiment, but were most prominent at late-intermediate time points. Signal transduction appeared to be an affected biological process in all but the late-intermediate phases; it seemed most profoundly altered during early stages. Many terms related to cell proliferation and DNA repair were enriched among late responder genes, but it should be noted that all these terms emerged from one single cell line, MDA-MB-361. The results from BMP7 data were very limited and may be

Table 2 Enriched gene ontology categories for differentially expressed genes as a result of BMP7 treatment.

\begin{tabular}{|c|c|c|}
\hline Category & Number of genes & $p$-Value \\
\hline \multicolumn{3}{|l|}{ Biological process } \\
\hline GO:0030182: neuron differentiation & 55 & 0.024 \\
\hline GO:0048730: epidermis morphogenesis & 8 & 0.025 \\
\hline GO:0051239: regulation of multicellular organismal process & 88 & 0.025 \\
\hline GO:0045944: positive regulation of transcription from RNA polymerase II promoter & 42 & 0.028 \\
\hline GO:0030855: epithelial cell differentiation & 24 & 0.031 \\
\hline GO:0016481: negative regulation of transcription & 50 & 0.033 \\
\hline GO:0035295: tube development & 32 & 0.042 \\
\hline \multicolumn{3}{|l|}{ Molecular function } \\
\hline GO:0043565: sequence-specific DNA binding & 57 & 0.024 \\
\hline GO:0003705: RNA polymerase II transcription factor activity, enhancer binding & 10 & 0.025 \\
\hline GO:0016564: transcription repressor activity & 38 & 0.038 \\
\hline
\end{tabular}




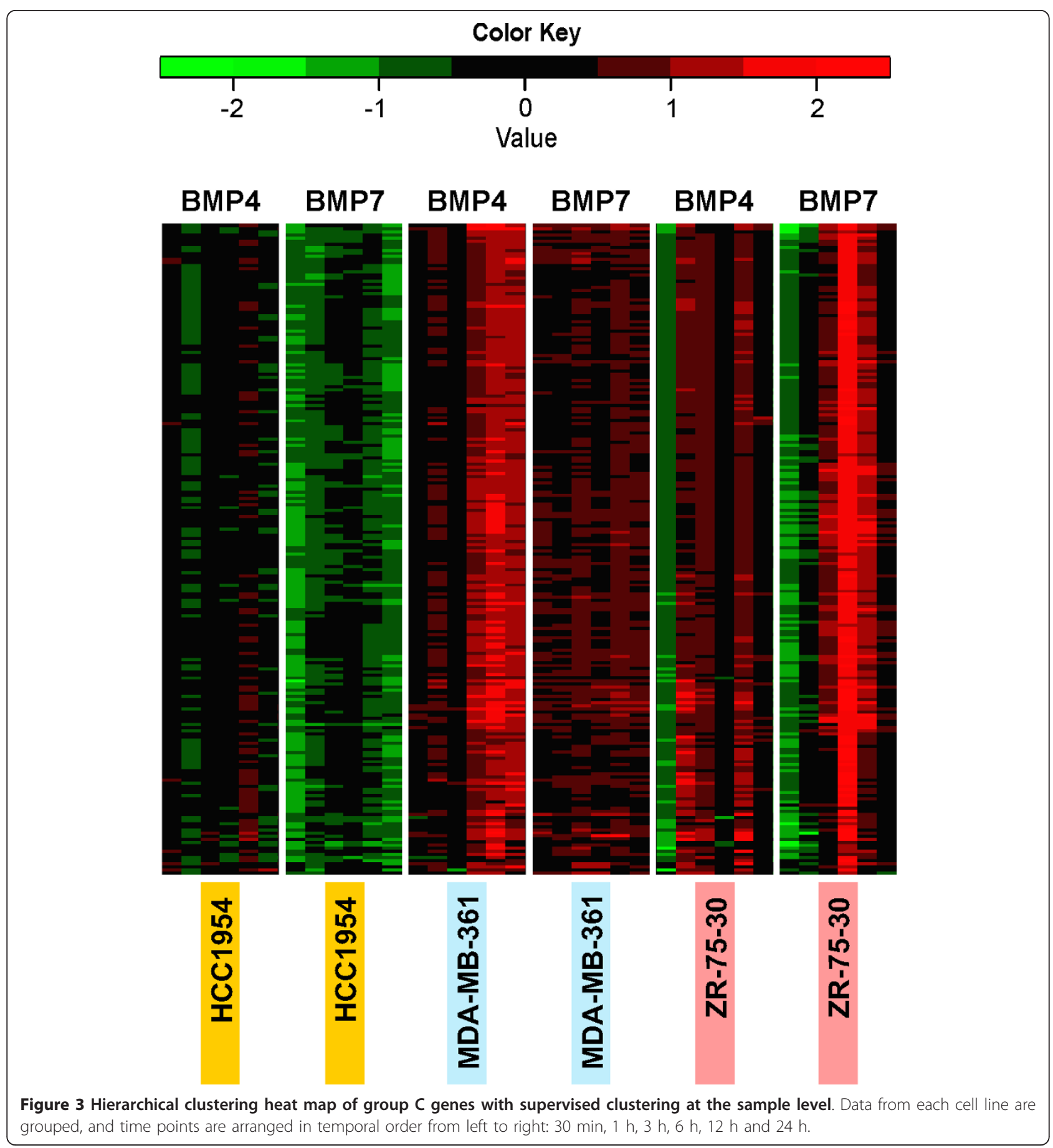

summarized as an enrichment of genes involved in regulation of metabolism and gene expression among the early-intermediate and late time categories.

Potential novel BMP target genes in breast cancer One of the main goals of this study was to identify new BMP4 and BMP7 target genes relevant in breast cancer. In order to distinguish those genes most often and ubiquitously regulated by BMP treatments, differentially expressed genes resulting from general filtering (1, 678 and 905 for BMP4 and BMP7 experiments, respectively) were ranked according to the number of times a gene was up- and downregulated throughout the series of cell lines and time points (Tables 5 and 6 and Additional file 4). It is interesting that although the proportion of up- and down-regulation events was roughly equal 
Table 3 Summary of the temporal clusters obtained from the analysis of BMP4 data.

\begin{tabular}{|c|c|c|c|c|c|c|c|c|c|c|}
\hline & \multicolumn{2}{|l|}{ Early } & \multicolumn{2}{|c|}{ Early-intermediate } & \multicolumn{2}{|c|}{ Late-intermediate } & \multicolumn{2}{|l|}{ Late } & \multicolumn{2}{|c|}{ Undetermined } \\
\hline & $\begin{array}{l}\text { cluster } \\
\text { ID }\end{array}$ & $\begin{array}{l}\text { genes/ } \\
\text { cluster }\end{array}$ & $\begin{array}{l}\text { cluster } \\
\text { ID }\end{array}$ & $\begin{array}{l}\text { genes/ } \\
\text { cluster }\end{array}$ & $\begin{array}{l}\text { cluster } \\
\text { ID }\end{array}$ & $\begin{array}{l}\text { genes/ } \\
\text { cluster }\end{array}$ & $\begin{array}{l}\text { cluster } \\
\text { ID }\end{array}$ & $\begin{array}{l}\text { genes/ } \\
\text { cluster }\end{array}$ & $\begin{array}{l}\text { cluster } \\
\text { ID }\end{array}$ & $\begin{array}{l}\text { genes/ } \\
\text { cluster }\end{array}$ \\
\hline$\overline{\mathrm{HCC} 1419}$ & 2 & 256 & 1 & 273 & 8 & 189 & 6 & 362 & 3 & 178 \\
\hline \multirow[t]{4}{*}{ (14 clusters) } & 5 & 148 & 4 & 341 & & & 11 & 353 & 7 & 152 \\
\hline & 10 & 107 & 14 & 31 & & & & & 9 & 224 \\
\hline & 12 & 157 & & & & & & & & \\
\hline & 13 & 132 & & & & & & & & \\
\hline Total & & 800 & & 654 & & 189 & & 715 & & 554 \\
\hline HCC1954 & 2 & 265 & 4 & 256 & 1 & 158 & 7 & 283 & & \\
\hline \multirow[t]{3}{*}{ (12 clusters) } & 5 & 353 & 9 & 258 & 3 & 419 & 10 & 156 & & \\
\hline & 6 & 108 & 11 & 244 & & & & & & \\
\hline & 8 & 110 & 12 & 251 & & & & & & \\
\hline Total & & 836 & & 1009 & & 577 & & 439 & & \\
\hline $\begin{array}{l}\text { MDA-MB- } \\
361\end{array}$ & 6 & 277 & 3 & 155 & 8 & 322 & 1 & 557 & 5 & 289 \\
\hline \multirow[t]{2}{*}{ (14 clusters) } & 13 & 215 & 7 & 177 & 9 & 487 & 2 & 483 & 10 & 362 \\
\hline & 14 & 355 & 12 & 270 & 11 & 554 & 4 & 564 & & \\
\hline Total & & 847 & & 602 & & 1363 & & 1604 & & 651 \\
\hline SK-BR-3 & 1 & 77 & 2 & 232 & 3 & 235 & 4 & 252 & & \\
\hline \multirow[t]{5}{*}{ (17 clusters) } & 6 & 70 & 10 & 402 & 7 & 365 & 5 & 300 & & \\
\hline & 11 & 148 & 14 & 383 & 8 & 1322 & & & & \\
\hline & 13 & 567 & 16 & 332 & 9 & 1104 & & & & \\
\hline & 17 & 51 & & & 12 & 95 & & & & \\
\hline & & & & & 15 & 508 & & & & \\
\hline Total & & 913 & & 1349 & & 3629 & & 552 & & \\
\hline ZR-75-30 & 1 & 601 & 9 & 140 & 4 & 2201 & 8 & 369 & 2 & 10 \\
\hline \multirow[t]{4}{*}{ (18 clusters) } & 5 & 107 & 10 & 780 & 14 & 185 & 11 & 688 & 3 & 10 \\
\hline & 12 & 53 & 18 & 436 & 16 & 809 & & & 6 & 9 \\
\hline & 15 & 227 & & & & & & & 7 & 9 \\
\hline & 17 & 1363 & & & & & & & 13 & 17 \\
\hline Total & & 2351 & & 1356 & & 3195 & & 1057 & & 55 \\
\hline
\end{tabular}

Gene clusters were classified in four temporal categories (early, early-intermediate, late-intermediate and late). Clusters with unclear profiles were classified as undetermined. The cluster ID column contains the ID number of the cluster.

when considering all the differentially expressed genes, induction of gene transcription clearly prevailed over inhibition when considering the 100 top-ranked genes (75\% and $73 \%$ of the events for BMP4 and BMP7, respectively). For BMP4, 80 genes were regulated in 10 or more events, while for BMP7, the analogous number of genes was 29 (Tables 5 and 6). Out of the 30 possible regulation events for a single gene ( 5 cell lines and 6 time points), the actual maximums were 23 events (PTPRG; protein tyrosine phosphatase, receptor type, G) for BMP4 and 19 events (GNRHR; gonadotropin-releasing hormone receptor) for BMP7 (Tables 5 and 6); all of these were upregulation events. As expected, several members of the Id family of inhibitors of DNA binding, well-known targets of BMPs [27], were strongly induced by both BMP ligands. In addition to PTPRG and GNRHR, other genes strongly upregulated by both ligands included APOC2 (apolipoprotein C-II) and an as-yet unnamed gene encoding an uncharacterized protein (C12orf42). DUSP2 (dual specificity phosphatase 2) and $M A P 3 K 5$ (mitogen-activated protein kinase kinase kinase 5) were highly induced only by BMP4. BMP7, on the other hand, strongly promoted the expression of genes including $P B X 1$ (pre-B-cell leukemia homeobox 1) and ZSCAN4 (zinc finger and SCAN domain containing $4)$, which were not among the genes most intensely regulated by BMP4.

\section{Discussion}

In recent years, it has become increasingly accepted that the deregulation of mechanisms normally involved in developmental processes has tumorigenic effects in adult tissues. One example is the BMP family of growth factors, whose function in cancer physiology has been 
Table 4 Summary of the temporal clusters obtained from the analysis of BMP7 data.

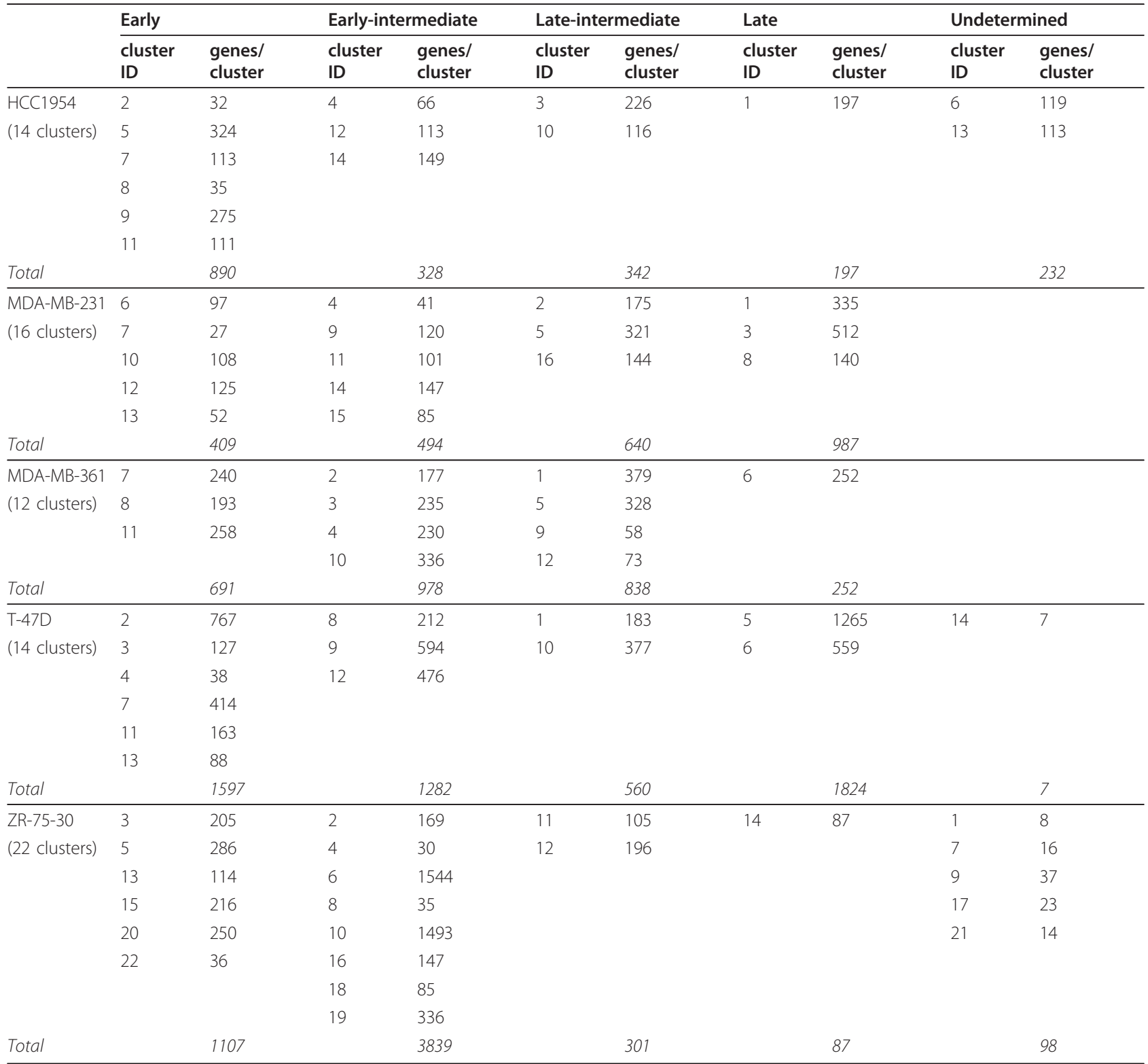

Gene clusters were classified in four temporal categories (early, early-intermediate, late-intermediate and late). Clusters with unclear profiles were classified as undetermined. The cluster ID column contains the ID number of the cluster.

demonstrated in many tumor types, including breast cancer [9-11]. In spite of this, little is known about BMP target genes in the context of tumors. The transcriptional responses of breast cancer cells to BMP signaling have been studied only minimally. More precisely, the effects of BMP2 and BMP7 treatments on transcription in MCF-7 and MDA-MB-468 breast cancer cell lines, respectively, have been analyzed using cDNA microarrays of limited content (from several hundreds to 14, 500 gene probes) [28-30]. In this study, we have therefore set up an experimental procedure to identify potential BMP target genes in breast cancer by studying the effects of two BMP ligands, BMP4 and BMP7, on genome-wide gene expression. These two BMPs were selected based on their essential role in breast cancer, which we and others have demonstrated in recent years [9-11]. Both ligands are highly expressed in primary breast carcinomas as well as in breast cancer cell lines [12-14,16,17]. BMP7 expression was also shown to be associated with early bone metastasis [15]. Additionally, in vitro studies have implicated BMP4 and BMP7 as important regulators of proliferation and migration of breast cancer cells [14,18,20,21,31].

Our experimental approach allowed multiple types of analyses and revealed interesting insights into how the 
A

\section{BMP4}

\section{Early}
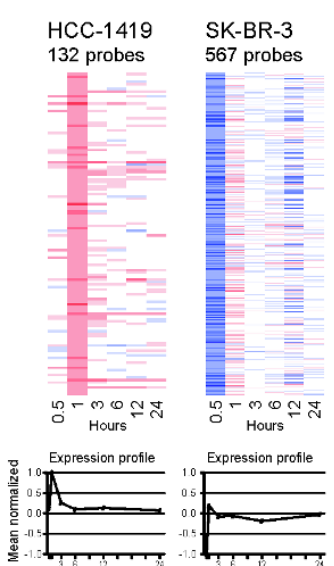

B

\section{BMP7}

\section{Early}

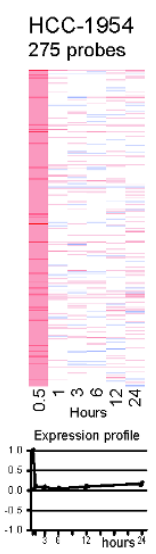

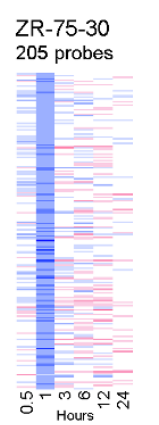

\section{Early-intermediate}

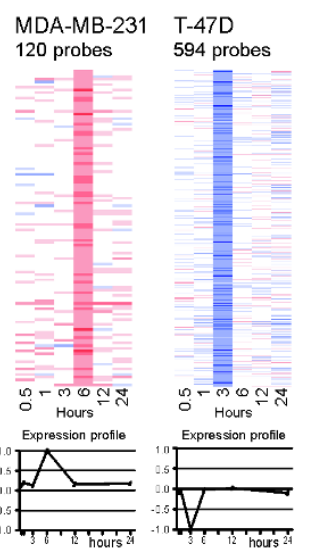

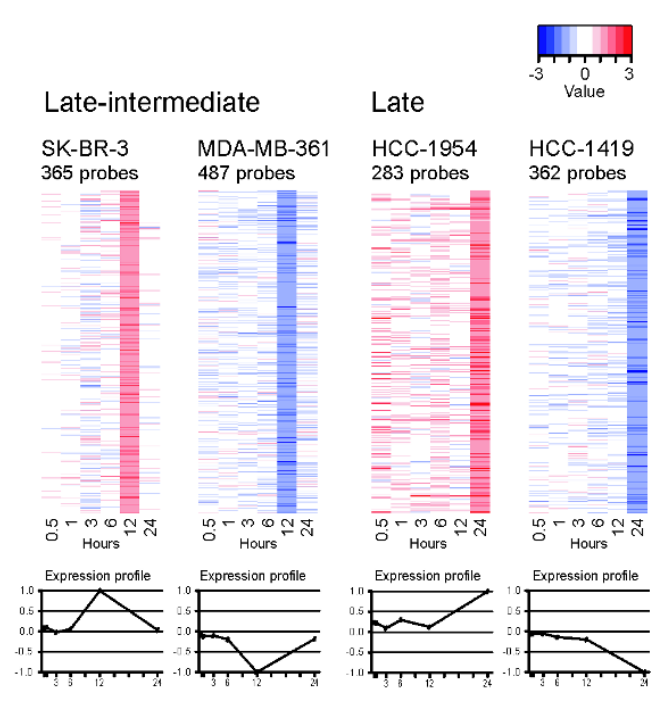

\section{C}
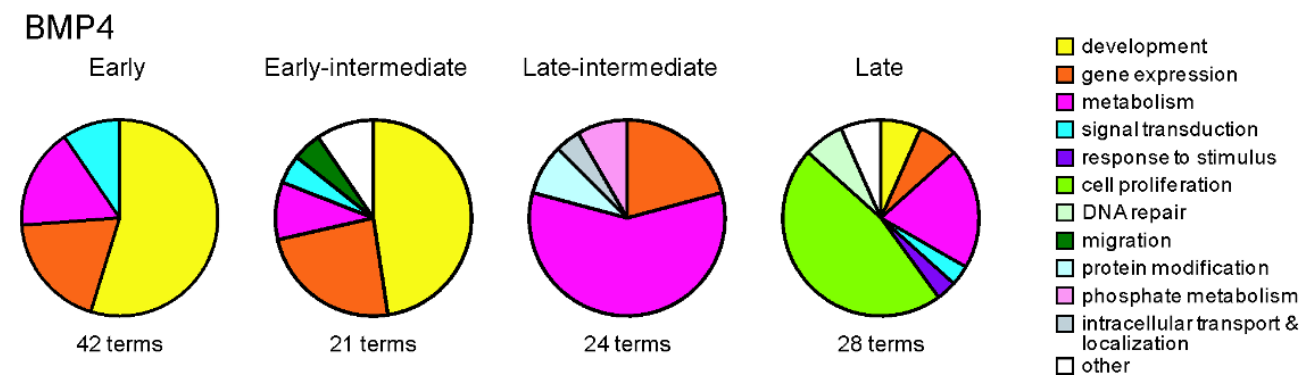

Figure 4 Time series analyses. Representative clusters from the four temporal categories are shown for BMP4 (A) and BMP7 (B). For each cluster, the upper figure shows the levels of differential expression through the time series for every probe. The lower chart represents the average value of differential expression for all the probes in the cluster along the time scale. The number of probes in each cluster is indicated under the cell line name. (C) GO analyses of the four temporal categories were performed, and data from the five cell lines were combined. The enriched GO terms for BMP4 are depicted. 
Table 5 Top most regulated genes after BMP4 signaling.

\begin{tabular}{|c|c|c|c|c|c|}
\hline \multirow[b]{2}{*}{ Gene Id } & \multirow[b]{2}{*}{ Gene name } & \multirow[b]{2}{*}{ Gene description } & \multicolumn{3}{|c|}{ \# regulated events } \\
\hline & & & Up & Down & Total \\
\hline ENSG00000144724 & PTPRG & protein tyrosine phosphatase, receptor type, $\mathrm{G}$ & 23 & 0 & 23 \\
\hline ENSG00000125968 & ID1 & inhibitor of DNA binding 1, dominant negative helix-loop-helix protein & 19 & 0 & 19 \\
\hline ENSG00000179088 & C12orf42 & uncharacterized protein C12orf42 & 19 & 0 & 19 \\
\hline ENSG00000158050 & DUSP2 & dual specificity phosphatase 2 & 18 & 0 & 18 \\
\hline ENSG00000109163 & GNRHR & gonadotropin-releasing hormone receptor & 18 & 0 & 18 \\
\hline ENSG00000234906 & APOC2 & apolipoprotein C-II & 18 & 0 & 18 \\
\hline ENSG00000117318 & ID3 & inhibitor of DNA binding 3, dominant negative helix-loop-helix protein & 17 & 0 & 17 \\
\hline ENSG00000115738 & ID2 & inhibitor of DNA binding 2, dominant negative helix-loop-helix protein & 16 & 0 & 16 \\
\hline ENSG00000172201 & ID4 & inhibitor of DNA binding 4, dominant negative helix-loop-helix protein & 16 & 0 & 16 \\
\hline ENSG00000197442 & MAP3K5 & mitogen-activated protein kinase kinase kinase 5 & 15 & 0 & 15 \\
\hline ENSG00000127129 & EDN2 & endothelin 2 & 15 & 0 & 15 \\
\hline ENSG00000164850 & GPER & G protein-coupled estrogen receptor 1 & 15 & 0 & 15 \\
\hline ENSG00000181638 & ZFP41 & zinc finger protein 41 homolog (mouse) & 15 & 0 & 15 \\
\hline ENSG00000181626 & ANKRD62 & ankyrin repeat domain 62 & 15 & 0 & 15 \\
\hline ENSG00000187957 & DNER & delta/notch-like EGF repeat containing & 14 & 0 & 14 \\
\hline ENSG00000238243 & OR2W3 & olfactory receptor, family 2 , subfamily $W$, member 3 & 14 & 0 & 14 \\
\hline ENSG00000164683 & HEY1 & hairy/enhancer-of-split related with YRPW motif 1 & 14 & 0 & 14 \\
\hline ENSG00000157322 & CLEC18A & C-type lectin domain family 18 , member $A$ & 13 & 1 & 14 \\
\hline ENSG00000247097 & C14orf184 & Putative uncharacterized protein C14orf184 & 8 & 6 & 14 \\
\hline ENSG00000212124 & TAS2R19 & taste receptor, type 2, member 19 & 9 & 4 & 13 \\
\hline ENSG00000186115 & CYP4F2 & cytochrome P450, family 4, subfamily F, polypeptide 2 & 6 & 7 & 13 \\
\hline ENSG00000176472 & ZNF575 & zinc finger protein 575 & 7 & 6 & 13 \\
\hline ENSG00000181722 & ZBTB20 & zinc finger and BTB domain containing 20 & 7 & 6 & 13 \\
\hline ENSG00000163827 & LRRC2 & leucine rich repeat containing 2 & 12 & 0 & 12 \\
\hline ENSG00000214049 & UCA1 & urothelial cancer associated 1 & 12 & 0 & 12 \\
\hline ENSG00000132854 & KANK4 & KN motif and ankyrin repeat domains 4 & 12 & 0 & 12 \\
\hline ENSG00000163749 & CCDC158 & coiled-coil domain containing 158 & 12 & 0 & 12 \\
\hline ENSG00000100029 & PES1 & pescadillo homolog 1, containing BRCT domain (zebrafish) & 0 & 12 & 12 \\
\hline ENSG00000120645 & IQSEC3 & IQ motif and Sec7 domain 3 & 0 & 12 & 12 \\
\hline ENSG00000122852 & SFTPA1 & surfactant protein A1 & 9 & 3 & 12 \\
\hline ENSG00000052802 & SC4MOL & sterol-C4-methyl oxidase-like & 9 & 3 & 12 \\
\hline ENSG00000197532 & OR6Y1 & olfactory receptor, family 6 , subfamily $Y$, member 1 & 8 & 4 & 12 \\
\hline ENSG00000078328 & RBFOX1 & RNA binding protein, fox-1 homolog (C. elegans) 1 & 8 & 4 & 12 \\
\hline ENSG00000185010 & F8 & coagulation factor VIII, procoagulant component & 8 & 4 & 12 \\
\hline ENSG00000115756 & HPCAL1 & hippocalcin-like 1 & 8 & 4 & 12 \\
\hline ENSG00000122859 & NEUROG3 & neurogenin 3 & 5 & 7 & 12 \\
\hline ENSG00000186810 & CXCR3 & chemokine (C-X-C motif) receptor 3 & 6 & 6 & 12 \\
\hline ENSG00000168874 & ATOH4 & atonal homolog 8 (Drosophila) & 11 & 0 & 11 \\
\hline ENSG00000040731 & $\mathrm{CDH} 10$ & cadherin 10 , type 2 (T2-cadherin) & 11 & 0 & 11 \\
\hline ENSG00000168930 & TRIM49 & tripartite motif-containing 49 & 11 & 0 & 11 \\
\hline ENSG00000104863 & LIN7B & lin-7 homolog B (C. elegans) & 11 & 0 & 11 \\
\hline ENSG00000113391 & FAM172A & microRNA 2277 & 11 & 0 & 11 \\
\hline ENSG00000162614 & NEXN & nexilin ( $F$ actin binding protein) & 11 & 0 & 11 \\
\hline ENSG00000120693 & SMAD9 & SMAD family member 9 & 11 & 0 & 11 \\
\hline ENSG00000176907 & C8orf4 & Uncharacterized protein C8orf4 (Thyroid cancer protein 1)(TC-1) & 10 & 1 & 11 \\
\hline ENSG00000085224 & ATRX & alpha thalassemia/mental retardation syndrome $\mathrm{X}$-linked & 10 & 1 & 11 \\
\hline ENSG00000163743 & $\mathrm{RCHY1}$ & ring finger and $\mathrm{CHY}$ zinc finger domain containing 1 & 9 & 2 & 11 \\
\hline ENSG00000006007 & GDE1 & glycerophosphodiester phosphodiesterase 1 & 9 & 2 & 11 \\
\hline ENSG00000114850 & SSR3 & signal sequence receptor, gamma (translocon-associated protein gamma) & 9 & 2 & 11 \\
\hline ENSG00000109472 & CPE & carboxypeptidase E & 9 & 2 & 11 \\
\hline
\end{tabular}


Table 5 Top most regulated genes after BMP4 signaling. (Continued)

\begin{tabular}{|c|c|c|c|c|c|}
\hline ENSG00000106608 & URGCP & upregulator of cell proliferation & 2 & 9 & 11 \\
\hline ENSG00000064201 & TSPAN32 & tetraspanin 32 & 8 & 3 & 11 \\
\hline ENSG00000212128 & TAS2R13 & taste receptor, type 2 , member 13 & 8 & 3 & 11 \\
\hline ENSG00000092871 & RFFL & ring finger and FYVE-like domain containing 1 & 7 & 4 & 11 \\
\hline ENSG00000139880 & $\mathrm{CDH} 24$ & cadherin 24 , type 2 & 4 & 7 & 11 \\
\hline ENSG00000039319 & ZFYVE16 & zinc finger, FYVE domain containing 16 & 4 & 7 & 11 \\
\hline ENSG00000206052 & DOK6 & docking protein 6 & 6 & 5 & 11 \\
\hline ENSG00000050165 & DKK3 & dickkopf homolog 3 (Xenopus laevis) & 5 & 6 & 11 \\
\hline ENSG00000115844 & DLX2 & distal-less homeobox 2 & 10 & 0 & 10 \\
\hline ENSG00000178343 & SHISA3 & shisa homolog 3 (Xenopus laevis) & 10 & 0 & 10 \\
\hline ENSG00000123329 & ARHGAP9 & Rho GTPase activating protein 9 & 10 & 0 & 10 \\
\hline ENSG00000145287 & PLAC8 & placenta-specific 8 & 10 & 0 & 10 \\
\hline ENSG00000187634 & SAMD11 & sterile alpha motif domain containing 11 & 10 & 0 & 10 \\
\hline ENSG00000167962 & ZNF598 & zinc finger protein 598 & 10 & 0 & 10 \\
\hline ENSG00000003509 & C2orf56 & Protein midA homolog, mitochondrial Precursor & 8 & 2 & 10 \\
\hline ENSG00000143153 & ATP1B1 & ATPase, $\mathrm{Na}+/ \mathrm{K}+$ transporting, beta 1 polypeptide & 8 & 2 & 10 \\
\hline ENSG00000189079 & ARID2 & AT rich interactive domain 2 (ARID, RFX-like) & 2 & 8 & 10 \\
\hline ENSG00000162706 & CADM3 & cell adhesion molecule 3 & 7 & 3 & 10 \\
\hline ENSG00000147488 & ST18 & suppression of tumorigenicity 18 (breast carcinoma) (zinc finger protein) & 7 & 3 & 10 \\
\hline ENSG00000182175 & RGMA & RGM domain family, member A & 7 & 3 & 10 \\
\hline ENSG00000163623 & NKX6-1 & NK6 homeobox 1 & 3 & 7 & 10 \\
\hline ENSG00000144559 & C3orf31 & MMP37-like protein, mitochondrial Precursor & 6 & 4 & 10 \\
\hline ENSG00000153002 & CPB1 & carboxypeptidase B1 (tissue) & 6 & 4 & 10 \\
\hline ENSG00000181965 & NEUROG1 & neurogenin 1 & 6 & 4 & 10 \\
\hline ENSG00000171564 & FGB & fibrinogen beta chain & 6 & 4 & 10 \\
\hline ENSG00000132612 & VPS4A & vacuolar protein sorting 4 homolog A (S. cerevisiae) & 6 & 4 & 10 \\
\hline ENSG00000183023 & SLC8A1 & solute carrier family 8 (sodium/calcium exchanger), member 1 & 4 & 6 & 10 \\
\hline ENSG00000166748 & AGBL1 & ATP/GTP binding protein-like 1 & 5 & 5 & 10 \\
\hline ENSG00000204882 & GPR20 & G protein-coupled receptor 20 & 5 & 5 & 10 \\
\hline ENSG00000159216 & RUNX1 & runt-related transcription factor 1 & 5 & 5 & 10 \\
\hline
\end{tabular}

Differentially expressed genes resulting from the general filtering of BMP4 data $(1,678)$ were ranked according to the number of times a gene was up- and downregulated throughout the series of cell lines and time points. Only those genes with total rank value of at least 10 are listed.

stimulation of BMP4 and BMP7 signaling influences the transcriptome of breast cancer cell lines. First of all, we showed relatively high numbers of DEPs as a result of BMP treatments, indicating a strong impact of BMP4 and BMP7 on the cell lines studied. Moreover, the transcriptional response to BMP4 was of a clearly higher magnitude than that induced by BMP7. Another aspect of the study was the opportunity to compare the effects of BMP signaling between cell lines. Interestingly, clear differences were seen in the amounts of DEPs, as well as in their expression patterns, as revealed by hierarchical clustering. BMP signaling pathways are regulated in a very complex manner and at many different levels, from the availability of BMP receptors, BMP ligands and BMP antagonists in the extracellular compartment to the presence or absence of various intracellular signal mediators and transcriptional co-activators or co-repressors [32,33]. Therefore, multiple factors influence the outcome of BMP signaling on the transcriptional level in a given cell. We have previously reported that all six BMP specific receptors (ACVR1, BMPR1A, BMPR1B, ACVR2A, ACVR2B, and BMPR2) are uniformly expressed among the breast cancer cell lines studied here [12]. Similarly, we have shown that SMAD4 is expressed and that phosphorylation of SMAD-1/5/8 is induced in these cell lines after BMP7 and BMP4 treatment $[14,21]$. Taken together, the expression profiles of BMP specific receptors or the mediators of the canonical intracellular pathway do not seem to have a major role in explaining the different transcriptional responses in the breast cancer cells. Nevertheless, due to the complexity of BMP signaling regulation, it is easy to understand that different cell lines may have different transcriptional responses to BMP stimulation. This observation highlights the importance of testing multiple cell lines when studying BMP signaling in cancer. An additional finding that could be inferred from our data is that induction of gene transcription, compared with 
Table 6 Top most regulated genes after BMP7 signaling.

\begin{tabular}{|c|c|c|c|c|c|}
\hline \multirow[b]{2}{*}{ Gene Id } & \multirow[b]{2}{*}{ Gene name } & \multirow[b]{2}{*}{ Gene description } & \multicolumn{3}{|c|}{ \# regulated events } \\
\hline & & & Up & Down & Total \\
\hline ENSG00000109163 & GNRHR & gonadotropin-releasing hormone receptor & 19 & 0 & 19 \\
\hline ENSG00000157322 & CLEC18A & C-type lectin domain family 18, member $\mathrm{A}$ & 16 & 1 & 17 \\
\hline ENSG00000179088 & C12orf42 & Uncharacterized protein C12orf42 & 15 & 0 & 15 \\
\hline ENSG00000123329 & ARHGAP9 & Rho GTPase activating protein 9 & 14 & 0 & 14 \\
\hline ENSG00000144724 & PTPRG & protein tyrosine phosphatase, receptor type, $G$ & 14 & 0 & 14 \\
\hline ENSG00000185630 & PBX1 & pre-B-cell leukemia homeobox 1 & 13 & 0 & 13 \\
\hline ENSG00000114850 & SSR3 & signal sequence receptor, gamma (translocon-associated protein gamma) & 9 & 4 & 13 \\
\hline ENSG00000186153 & WWOX & WW domain containing oxidoreductase & 5 & 8 & 13 \\
\hline ENSG00000234906 & APOC2 & apolipoprotein C-II & 12 & 0 & 12 \\
\hline ENSG00000180532 & ZSCAN4 & zinc finger and SCAN domain containing 4 & 12 & 0 & 12 \\
\hline ENSG00000144711 & IQSEC1 & IQ motif and Sec7 domain 1 & 12 & 0 & 12 \\
\hline ENSG00000138821 & SLC39A8 & solute carrier family 39 (zinc transporter), member 8 & 11 & 1 & 12 \\
\hline ENSG00000165995 & CACNB2 & calcium channel, voltage-dependent, beta 2 subunit & 3 & 9 & 12 \\
\hline ENSG00000122859 & NEUROG3 & neurogenin 3 & 8 & 4 & 12 \\
\hline ENSG00000212128 & TAS2R13 & taste receptor, type 2 , member 13 & 6 & 6 & 12 \\
\hline ENSG00000184999 & SLC22A10 & solute carrier family 22, member 10 & 11 & 0 & 11 \\
\hline ENSG00000183914 & DNAH2 & dynein, axonemal, heavy chain 2 & 11 & 0 & 11 \\
\hline ENSG00000125968 & ID1 & inhibitor of DNA binding 1, dominant negative helix-loop-helix protein & 11 & 0 & 11 \\
\hline ENSG00000167962 & ZNF598 & zinc finger protein 598 & 10 & 1 & 11 \\
\hline ENSG00000181722 & ZBTB20 & zinc finger and BTB domain containing 20 & 3 & 8 & 11 \\
\hline ENSG00000091482 & SMPX & small muscle protein, $\mathrm{X}$-linked & 10 & 0 & 10 \\
\hline ENSG00000117318 & ID3 & inhibitor of DNA binding 3, dominant negative helix-loop-helix protein & 10 & 0 & 10 \\
\hline ENSG00000163694 & RBM47 & RNA binding motif protein 47 & 10 & 0 & 10 \\
\hline ENSG00000006007 & GDE1 & glycerophosphodiester phosphodiesterase 1 & 9 & 1 & 10 \\
\hline ENSG00000164104 & HMGB2 & high-mobility group box 2 & 8 & 2 & 10 \\
\hline ENSG00000250589 & DUX4 & double homeobox 4 & 2 & 8 & 10 \\
\hline ENSG00000130559 & CAMSAP1 & calmodulin regulated spectrin-associated protein 1 & 3 & 7 & 10 \\
\hline ENSG00000166501 & PRKCB & protein kinase $\mathrm{C}$, beta & 4 & 6 & 10 \\
\hline ENSG00000186115 & CYP4F2 & cytochrome P450, family 4, subfamily F, polypeptide 2 & 4 & 6 & 10 \\
\hline
\end{tabular}

Differentially expressed genes resulting from the general filtering of BMP7 data (905) were ranked according to the number of times a gene was up- and downregulated throughout the series of cell lines and time points. Only those genes with total rank value of at least 10 are listed.

inhibition, was the common response among those genes most frequently regulated by BMP4 and BMP7 in breast cancer cells. Likewise, previous microarray-based transcriptomic analyses of TGF- $\beta$ and BMP have shown that induction of gene expression is the predominant response of mammalian cells to stimulation by these growth factors [28,30,33-35].

After BMP4 and BMP7 stimulation, the microarray analyses identified a large number of differentially expressed genes in our panel of cell lines. To explore the biological functions of these genes, GO enrichment analyses were performed. These revealed very similar results for both BMP ligands, namely, regulation of transcription and developmental processes. It seems, therefore, that the functions most prevalently influenced by BMP signaling in breast cancer cells do not differ remarkably from conventional roles that BMPs possess during development [36,37].
Synexpression groups are synchronously coexpressed gene sets, particularly apparent during embryonic development and in the response of cells to hormones and growth factors $[38,39]$. Our analyses unveiled that treatment of breast cancer cells with either BMP4 or BMP7 resulted in the coordinated expression of a group of genes (clusters A and B, respectively). Most interestingly, a considerable number of the genes in these two synexpression groups were common for the two ligands (group C). Moreover, our data indicated that treatment of a cell line with either BMP4 or BMP7 results in similar transcriptional responses of group $C$ genes. We therefore hypothesize that group $C$ represents molecular responses shared by the BMP4 and BMP7 signaling pathways. This finding prompted us to ask what functions these common genes fulfill in the cell. GO enrichment analysis of the genes in group $C$ revealed that these genes are involved in two main biological 
processes, regulation of gene expression and regulation of development and morphogenesis. These results support the notion that genes known to regulate development also have functions that are important for the maintenance of cancer cells.

We also studied the temporal patterns of the transcriptional response after BMP treatment. The number of DEPs showed a tendency to increase with time, a trend previously noticed in transcriptome analysis of TGF- $\beta$ family members in murine mammary epithelial cells and in breast cancer cells $[29,35]$. The DEPs could be grouped according to their temporal pattern of expression, varying from early to late responders. These temporal clusters were found in every cell line, and some of them even contained over a thousand gene elements. The next logical step was to explore whether there was a time-dependent shift in the distribution of gene functions. Although GO enrichment results were not obtained for all the probe clusters of all the cell lines, interesting features could be identified, especially in the case of the BMP4 data. Transcriptional regulation in the first 6 hours concentrated most notably on genes involved in developmental processes, metabolic processes, gene expression and signal transduction. Gene expression was also well-represented after 12 hours, while metabolism became by far the most prominent function at this time point. Most interestingly, 24 hours after BMP4 stimulation there was an evident overrepresentation of genes involved in cell proliferation, although this phenomenon was observed exclusively in MDA-MB-361 cells. All in all, the enriched biological functions indeed fluctuated in time and in a logical sequence, with regulation of gene expression and signal transduction leading to changes in metabolism and finally to regulation of cell proliferation, a phenotype relevant for cancer cell physiology. The fact that we did not see enrichment of cell proliferation-associated functions in more than one cell line could be due to differences in the speed of BMP signaling in different cell lines. Even though a longer experiment certainly could have clarified this issue, we concentrated our analysis on the first 24 hours after BMP treatment because we were interested primarily in the identification of BMP target genes.

As mentioned, one of the main goals of this study was to identify potential novel gene targets of BMP signaling relevant in breast cancer. We provided lists of candidate genes that are strongly and rather uniformly regulated by BMP4 or BMP7 throughout the cell lines and time points. Some of them, such as members of the Id family of inhibitors of DNA binding, are well-known BMP target genes $[27,29]$. Id proteins are transcription factors that regulate cell growth and differentiation [40], and all four members of the protein family play crucial roles in various aspects of normal and malignant breast biology [41]. Others are newly linked, in this work, to BMP signaling, and some of these genes have interesting connections with tumor biology, such as PTPRG or DUSP2. A positive feedback regulation where BMP treatment leads to increased expression of BMP antagonists is known to exist. In our study, no consistent expression changes were observed for any of the known BMP antagonists, such as noggin, gremlin, sclerostin and follistatin. Previous studies have shown a wide time window in the induction of e.g. noggin expression in different tissues after BMP treatment, ranging from 1 to 48 hours $[42,43]$. Thus it is possible that the feedback effect in the breast cancer cells was not evident at time points analyzed here.

Protein tyrosine phosphatases (PTPs) are key regulators of the cellular protein phosphorylation balance, critical in the control of a wide spectrum of physiological processes such as cell proliferation, differentiation, transformation, transport and locomotion. Subsequently, aberrations in phosphorylation processes play a major role in the pathogenesis of numerous diseases, including cancer $[44,45]$. PTPRG is a receptor-type PTP implicated as a candidate tumor suppressor gene in several types of tumors, including breast cancer $[46,47]$. In MCF-7 breast cancer cells, PTPRG inhibits proliferation and anchorage-independent growth and reduces tumor formation in a xenograft model $[47,48]$. Delayed cell cycle re-entry by increasing the level of cell cycle regulators p21 and p27 could explain the inhibitory effect of PTPRG on cell growth [47]. Based on the above, upregulation of PTPRG in BMP-stimulated cancer cells could contribute to the observed BMP-induced antiproliferative effect $[14,21]$. DUSP2 also belongs to the PTP family of phosphatases. It is a mitogen-activated protein kinase (MAPK) phosphatase (MKP) that dephosphorylates both threonine and tyrosine residues within target MAPKs leading to their deactivation. MAPK signaling controls cellular processes such as proliferation, differentiation, migration and apoptosis [48]. Therefore, abnormal MKP activity, and hence anomalous MAPK signaling, has important consequences for processes critical to the development and progression of human cancer. The role of DUSP2 in cancer has been examined in only a few studies, and data are controversial. Overexpression of DUSP2 expression was found in 37 of 39 malignant effusions from serous ovarian carcinoma patients and was associated with poor survival [49]. By contrast, decreased DUSP2 transcript levels were reported in cancerous breast, colon, lung, ovary, kidney and prostate tissues, and reduced DUSP2 protein levels were observed in cervical and colon cancer [50]. Additionally, DUSP2 suppression was associated with tumorigenesis and malignancy in colon cancer, and DUSP2 
overexpression induced apoptosis and inhibited tumor growth in HeLa cells in vitro and in xenograft models [51].

\section{Conclusions}

All in all, we show that BMP4 and BMP7 have strong effects on gene expression in breast cancer cells, and that this transcriptional response and its functional outcome follow a temporal sequence. Our data support the existence of a synexpression group of regulated genes that represent the core molecular responses shared by BMP4 and BMP7 signaling pathways. Additionally, we provide a list of potential novel BMP target genes relevant in breast cancer.

\section{Additional material}

Additional file 1: List of probes in group $\mathbf{C}$. The expression values are represented as log2 ratios. Data was colored according to the accompanying color key. The data sheet contains 210 probes.

Additional file 2: GO enrichment results for group $\mathrm{C}$ genes

Additional file 3: Model-based clustering results and GO

enrichment. The probe clusters obtained are represented as well as the results of the GO enrichment analyses. GO terms are colored according to the accompanying color key.

Additional file 4: Most commonly regulated genes with rank 6 or higher. The expression values are represented as log2 ratios. Data was colored according to the accompanying color key. The data sheets contain 608 and 281 genes for BMP4 and BMP7, respectively.

\section{Acknowledgements}

The authors greatly appreciate the skillful assistance of Ms. Kati Rouhento. This study was partly supported by grants from the Competitive Research Funding of the Tampere University Hospital, the Sigrid Jusélius Foundation, the Finnish Cancer Organizations, the Academy of Finland (project: 125826) and Biocentrum Helsinki.

\section{Author details}

'Laboratory of Cancer Genetics, Institute of Biomedical Technology, University of Tampere and Centre for Laboratory Medicine, Tampere University Hospital, Finland. ${ }^{2}$ Computational Systems Biology Laboratory, Genome-Scale Biology Research Program, Institute of Biomedicine, University of Helsinki, Finland.

\section{Authors' contributions}

ARM participated in the design of the study, carried out the interpretation of the data analyses and drafted the manuscript. ELA was responsible for conception and design of the project and participated in writing the manuscript. LS performed computational data analyses and participated in writing the manuscript. JK performed the microarray hybridizations. KN performed computational data analyses. SH supervised and coordinated the computational data analyses and participated in writing the manuscript. AK was responsible for conception and coordination of the project and participated in writing the manuscript. All authors read and approved the final manuscript.

\section{Competing interests}

The authors declare that they have no competing interests.

Received: 12 September 2011 Accepted: 25 November 2011 Published: 25 November 2011

\section{References}

1. Schmierer B, Hill CS: TGFbeta-SMAD signal transduction: molecular specificity and functional flexibility. Nat Rev Mol Cell Biol 2007, 8:970-982

2. Nohe A, Keating E, Knaus P, Petersen NO: Signal transduction of bone morphogenetic protein receptors. Cell Signal 2004, 16:291-299.

3. Derynck $R$, Zhang YE: Smad-dependent and Smad-independent pathways in TGF-beta family signalling. Nature 2003, 425:577-584.

4. Attisano L, Labbe E: TGFbeta and Wnt pathway cross-talk. Cancer Metastasis Rev 2004, 23:53-61.

5. Miyazono K, Maeda S, Imamura T: BMP receptor signaling: transcriptional targets, regulation of signals, and signaling cross-talk. Cytokine Growth Factor Rev 2005, 16:251-263.

6. Herpin A, Cunningham C: Cross-talk between the bone morphogenetic protein pathway and other major signaling pathways results in tightly regulated cell-specific outcomes. Febs J 2007, 274:2977-2985.

7. Wozney JM, Rosen V, Celeste AJ, Mitsock LM, Whitters MJ, Kriz RW, Hewick RM, Wang EA: Novel regulators of bone formation: molecular clones and activities. Science 1988, 242:1528-1534.

8. Hogan BL: Bone morphogenetic proteins: multifunctional regulators of vertebrate development. Genes Dev 1996, 10:1580-1594.

9. Thawani JP, Wang AC, Than KD, Lin CY, La Marca F, Park P: Bone morphogenetic proteins and cancer: review of the literature. Neurosurgery 2010, 66:233-246, discussion 246.

10. Singh A, Morris RJ: The Yin and Yang of bone morphogenetic proteins in cancer. Cytokine Growth Factor Rev 2010, 21:299-313.

11. Alarmo EL, Kallioniemi A: Bone morphogenetic proteins in breast cancer: dual role in tumourigenesis? Endocr Relat Cancer 2010, 17:R123-139.

12. Alarmo EL, Kuukasjarvi T, Karhu R, Kallioniemi A: A comprehensive expression survey of bone morphogenetic proteins in breast cancer highlights the importance of BMP4 and BMP7. Breast Cancer Res Treat 2007, 103:239-246.

13. Schwalbe M, Sanger J, Eggers R, Naumann A, Schmidt A, Hoffken K, Clement $\mathrm{JH}$ : Differential expression and regulation of bone morphogenetic protein 7 in breast cancer. Int J Oncol 2003, 23:89-95.

14. Ketolainen JM, Alarmo EL, Tuominen VJ, Kallioniemi A: Parallel inhibition of cell growth and induction of cell migration and invasion in breast cancer cells by bone morphogenetic protein 4. Breast Cancer Res Treat 2010.

15. Alarmo EL, Korhonen T, Kuukasjarvi T, Huhtala H, Holli K, Kallioniemi A: Bone morphogenetic protein 7 expression associates with bone metastasis in breast carcinomas. Ann Oncol 2008, 19:308-314.

16. Alarmo EL, Rauta J, Kauraniemi P, Karhu R, Kuukasjarvi T, Kallioniemi A: Bone morphogenetic protein 7 is widely overexpressed in primary breast cancer. Genes Chromosomes Cancer 2006, 45:411-419.

17. Schwaninger $R$, Rentsch CA, Wetterwald A, van der Horst $G$, van Bezooijen RL, van der Pluijm G, Lowik CW, Ackermann K, Pyerin W, Hamdy FC, et al: Lack of noggin expression by cancer cells is a determinant of the osteoblast response in bone metastases. Am J Pathol 2007, 170:160-175.

18. Buijs JT, Henriquez NV, van Overveld PG, van der Horst G, Que I, Schwaninger R, Rentsch C, Ten Dijke P, Cleton-Jansen AM, Driouch K, et al: Bone morphogenetic protein 7 in the development and treatment of bone metastases from breast cancer. Cancer Res 2007, 67:8742-8751.

19. Montesano R: Bone morphogenetic protein-4 abrogates lumen formation by mammary epithelial cells and promotes invasive growth. Biochem Biophys Res Commun 2007, 353:817-822.

20. Shon SK, Kim A, Kim JY, Kim Kl, Yang Y, Lim JS: Bone morphogenetic protein-4 induced by NDRG2 expression inhibits MMP-9 activity in breast cancer cells. Biochem Biophys Res Commun 2009, 385:198-203.

21. Alarmo EL, Parssinen J, Ketolainen JM, Savinainen K, Karhu R, Kallioniemi A: BMP7 influences proliferation, migration, and invasion of breast cancer cells. Cancer Lett 2009, 275:35-43.

22. csbl.go: Semantic similarity based on Gene Ontology. [http://csbi.ltdk. helsinki.fi/csbl.go].

23. Fraley C, Raftery AE: Model based clustering, discriminant analysis, and density estimation. J Am Stat Assoc 2002, 97:611-631.

24. Yeung KY, Fraley C, Murua A, Raftery AE, Ruzzo WL: Model-based clustering and data transformations for gene expression data. Bioinformatics 2001, 17:977-987

25. Ovaska K, Laakso M, Haapa-Paananen S, Louhimo R, Chen P, Aittomaki V, Valo E, Nunez-Fontarnau J, Rantanen V, Karinen S, et al: Large-scale data 
integration framework provides a comprehensive view on glioblastoma multiforme. Genome Med 2010, 2:65.

26. R_Development_Core_Team: R: A language and environment for statistical computing. Vienna, Austria: R Foundation for Statistical Computing; 2011.

27. Hollnagel A, Oehlmann V, Heymer J, Ruther U, Nordheim A: Id genes are direct targets of bone morphogenetic protein induction in embryonic stem cells. J Biol Chem 1999, 274:19838-19845

28. Kowanetz M, Valcourt U, Bergstrom R, Heldin CH, Moustakas A: Id2 and Id3 define the potency of cell proliferation and differentiation responses to transforming growth factor beta and bone morphogenetic protein. Mol Cell Biol 2004, 24:4241-4254.

29. Clement JH, Marr N, Meissner A, Schwalbe M, Sebald W, Kliche KO, Hoffken K, Wolfl S: Bone morphogenetic protein 2 (BMP-2) induces sequential changes of Id gene expression in the breast cancer cell line MCF-7. J Cancer Res Clin Oncol 2000, 126:271-279.

30. Steinert S, Kroll TC, Taubert I, Pusch L, Hortschansky P, Hoffken K, Wolf S, Clement JH: Differential expression of cancer-related genes by single and permanent exposure to bone morphogenetic protein 2. J Cancer Res Clin Oncol 2008, 134:1237-1245.

31. Takahashi M, Otsuka F, Miyoshi T, Otani H, Goto J, Yamashita M, Ogura T, Makino H, Doihara H: Bone morphogenetic protein 6 (BMP6) and BMP7 inhibit estrogen-induced proliferation of breast cancer cells by suppressing p38 mitogen-activated protein kinase activation. J Endocrinol 2008, 199:445-455

32. Zeng S, Chen J, Shen $\mathrm{H}$ : Controlling of bone morphogenetic protein signaling. Cell Signal 2010, 22:888-893.

33. Massague J, Seoane J, Wotton D: Smad transcription factors. Genes Dev 2005, 19:2783-2810.

34. de Jong DS, Steegenga WT, Hendriks JM, van Zoelen EJ, Olijve W, Dechering KJ: Regulation of Notch signaling genes during BMP2-induced differentiation of osteoblast precursor cells. Biochem Biophys Res Commun 2004, 320:100-107.

35. Valcourt U, Kowanetz M, Niimi H, Heldin CH, Moustakas A: TGF-beta and the Smad signaling pathway support transcriptomic reprogramming during epithelial-mesenchymal cell transition. Mol Biol Cell 2005, 16:1987-2002.

36. Chen D, Zhao M, Mundy GR: Bone morphogenetic proteins. Growth Factors 2004, 22:233-241.

37. Gazzerro E, Canalis E: Bone morphogenetic proteins and their antagonists. Rev Endocr Metab Disord 2006, 7:51-65.

38. Baldessari $D$, Shin $Y$, Krebs $O$, Konig R, Koide $T$, Vinayagam A, Fenger $U$, Mochii M, Terasaka C, Kitayama A, et al: Global gene expression profiling and cluster analysis in Xenopus laevis. Mech Dev 2005, 122:441-475.

39. Karaulanov E, Knochel W, Niehrs C: Transcriptional regulation of BMP4 synexpression in transgenic Xenopus. Embo J 2004, 23:844-856.

40. Norton JD, Deed RW, Craggs G, Sablitzky F: Id helix-loop-helix proteins in cell growth and differentiation. Trends Cell Biol 1998, 8:58-65.

41. de Candia P, Benera R, Solit DB: A role for Id proteins in mammary gland physiology and tumorigenesis. Adv Cancer Res 2004, 92:81-94.

42. Stottmann RW, Anderson RM, Klingensmith J: The BMP antagonists chordin and noggin have essential but redundant roles in mouse mandibular outgrowth. Dev Biol 2001, 240:457-473.

43. Haudenschild DR, Palmer SM, Moseley TA, You Z, Reddi AH: Bone morphogenetic protein (BMP)-6 signaling and BMP antagonist noggin in prostate cancer. Cancer Res 2004, 64:8276-8284.

44. Yi T, Lindner D: The role and target potential of protein tyrosine phosphatases in cancer. Curr Oncol Rep 2008, 10:114-121.

45. Julien SG, Dube N, Hardy S, Tremblay ML: Inside the human cancer tyrosine phosphatome. Nat Rev Cancer 2011, 11:35-49.

46. LaForgia S, Morse B, Levy J, Barnea G, Cannizzaro LA, Li F, Nowell PC, Boghosian-Sell L, Glick J, Weston A, et al: Receptor protein-tyrosine phosphatase gamma is a candidate tumor suppressor gene at human chromosome region 3p21. Proc Natl Acad Sci USA 1991, 88:5036-5040.

47. Shu ST, Sugimoto Y, Liu S, Chang HL, Ye W, Wang LS, Huang YW, Yan P, Lin YC: Function and regulatory mechanisms of the candidate tumor suppressor receptor protein tyrosine phosphatase gamma (PTPRG) in breast cancer cells. Anticancer Res 2010, 30:1937-1946.

48. Liu S, Sugimoto Y, Sorio C, Tecchio C, Lin YC: Function analysis of estrogenically regulated protein tyrosine phosphatase gamma
(PTPgamma) in human breast cancer cell line MCF-7. Oncogene 2004, 23:1256-1262.

49. Chang L, Karin M: Mammalian MAP kinase signalling cascades. Nature 2001, 410:37-40

50. Givant-Horwitz V, Davidson B, Goderstad JM, Nesland JM, Trope CG, Reich R: The PAC-1 dual specificity phosphatase predicts poor outcome in serous ovarian carcinoma. Gynecol Oncol 2004, 93:517-523.

51. Lin SC, Chien CW, Lee JC, Yeh YC, Hsu KF, Lai YY, Lin SC, Tsai SJ: Suppression of dual-specificity phosphatase-2 by hypoxia increases chemoresistance and malignancy in human cancer cells. J Clin Invest 2011, 121:1905-1916.

\section{Pre-publication history}

The pre-publication history for this paper can be accessed here: http://www.biomedcentral.com/1755-8794/4/80/prepub

doi:10.1186/1755-8794-4-80

Cite this article as: Rodriguez-Martinez et al:: Analysis of BMP4 and BMP7 signaling in breast cancer cells unveils time-dependent transcription patterns and highlights a common synexpression group of genes. BMC Medical Genomics 2011 4:80.

\section{Submit your next manuscript to BioMed Central and take full advantage of:}

- Convenient online submission

- Thorough peer review

- No space constraints or color figure charges

- Immediate publication on acceptance

- Inclusion in PubMed, CAS, Scopus and Google Scholar

- Research which is freely available for redistribution 